on individuals, as I do too in my current efforts to improve surgical care in remote parts of Nepal by on-thejob training using local resources. We both get our hands dirty. Can we also act as missionaries in the second sense? I have tried in my editorial to persuade others to view health in a structural sense, to dirty their hands in the economic-political area. Perhaps Dr. Lluberas does the same in talking to others about his experiences in Haiti, a country that was the richest part of the Americas 500 years ago at the time of first contact with Europe. Today it is the poorest country in this hemisphere, in large part as a result of US policies that continue to this day.

I considered Dr. Rees' organization, African Medical and Research Foundation, to be a source of valuable ideas when I worked in a remote Himalayan Valley in Nepal in the 1970s. The issues raised by Dr. Rees reflect what I term "the medical touristic transaction." As medical tourists, we primarily relate to and influence an elite class of people in those countries, privileged doctors, and not the poor majority. This elite is very sensitive to the wealth/income gap between the rich and poor countries, but for the most part they are not concerned with the inequalities within their own country. With the structural adjustment programs promulgated by the major financial institutions in third world countries, the medical elite has seen their incomes stagnate or decline unless they can develop a lucrative private practice.

We come with a background in chronic diseases, the major problems back home. Our clinical approaches are based on expensive technology, and pharmaceuticals, as well as increasingly complicated procedures. The elite counterparts we work with are eager to improve their capabilities with ultrasound, endoscopy, cancer chemotherapies and other modern techniques used in rich countries. Part of their interest is to acquire skills to make their private practices more profitable. They see their practices as helping decrease the gap between themselves and their rich-country counterparts. They also try to influence government spending, as witnessed by the many tertiary care hospitals that are built by third world governments for their elite who do not have recourse to health insurance to cover such expenses. Cardiac care, cancer hospitals, and other specialty units are springing up to further limit the distribution of minimal services for the poorest. The doctors' contact with us also makes easier their emigration to a rich country.

Dr. Rees rightly points out the value to us of being medical tourists. Nothing has influenced my life as much as my contact with Nepal. I gained insight into the hearts and minds of the Rai family living in a grass hut on a mountainside, starting fires with flint and steel, and carrying water in bamboo canisters. I faced clinical chal- lenges side by side with Nepali doctors in remote district hospitals and for these experiences I am profoundly grateful. But there is a price.

More and more countries worldwide are trying to adopt the US model of 'damaged care,' and like it or not, we are salespeople for this non-system. I agree that the bilateral and multilateral "aid" doesn't serve the needs of most third world people. But we can't assume that medical tourism is the answer. We must strive to work for structural medicine, both locally and globally, to further a system of justice that limits planned inequalities to those that benefit the least advantaged. As Pogo said, "We have met the enemy and he is us."

Stephen Bezruchka MD, MPH Seattle, WA, USA

\section{A personal account of high-altitude pulmonary edema}

\section{To the Editor:}

Four years ago I flew to Cuzco, Peru, to take part in a wilderness medical conference and hike the Inca Trail. I had no symptoms of altitude illness during my initial stay in Cuzco (altitude 11200 feet) or subsequently on the Inca Trail, even though we reached an altitude of 13776 feet at Warmiwanusqa Pass (Pass of the Dead Woman). We arrived at Machu Picchu (7710 feet), spent the night at Aquas Caliente (6400 feet), returned to Machu Picchu the next morning, and took the train to Cuzco that evening.

That night, in Cuzco, I was awakened a number of times by periodic breathing - a sense of suffocation I found most unpleasant. I took no medication until the following evening, when I was awakened by similar symptoms, became nauseated, and vomited once. (I do not recall a headache, but I commonly have vascular headaches and may have taken medication without attributing the headache to altitude.) I immediately took a 250-mg, sustained-release capsule of acetazolamide and had no further symptoms.

In discussions with physicians knowledgeable about altitude illnesses, we concluded this episode apparently was a case of "re-entry" acute mountain sickness. None of us had previously encountered this type of illness, although we were quite familiar with re-entry high-altitude pulmonary edema (HAPE). It seems unlikely that this was simply altitude intolerance, because I encountered no altitude problems while hiking Kilimanjaro (19340 feet) the previous year, and I do not get acute mountain sickness when skiing in Colorado or Utah. 
In August 2000 I returned to Cuzco, had no altitude illness, took the train to Machu Picchu, spent 24 hours there, and was awakened by periodic breathing the evening after I returned to Cuzco, apparently another instance of re-entry acute mountain sickness. I immediately took $125 \mathrm{mg}$ of acetazolamide and had no further symptoms.

However, after 5 days of acclimatization in Cuzco, I flew to Lima at sea level, traveled by car along the coast for about 3 hours, ascended to Conococha Pass at 13120 feet, and dropped down to Huaraz at 10140 feet. The following day our small group took a minivan through Portachuelo (Beautiful Pass) de Llanganuco at 15580 feet, and camped at about 12300 feet. The next day we descended to about 12000 feet before hiking to 12700 feet, where I developed a disorder I consider HAPE.

In retrospect, my first symptom was increased fatigue. I was surprised that I was having so much difficulty with the ascent to 12700 feet and was depressed that my dreams of accomplishing several more significant climbs before age forced me to quit seemed out of reach. (I am 65.) That afternoon, I noticed a tachycardia of 104, although it had decreased to 92 by dinnertime. I spent a restless night and my pulse remained elevated. Near morning it was 110. I was not breathing faster than my wife, who shared my tent, but seemed to be breathing more deeply. However, when I got up about 5 AM to use the toilet (a small hole in the ground) and subsequently while packing my gear in my tent, I was gasping for breath.

I had no headache or cough. No one had a stethoscope, and we did not try to listen for rales. However, an emergency physician in our group observed that I was definitely short of breath. Because we were scheduled to go over a 15711-foot pass and spend the next evening at 13200 feet, descent seemed prudent. While walking out, I noticed that I became quite short of breath while ascending small hills (30 feet or so), although I had little difficulty walking on level ground or downhill. A horse was hired to carry me the last half of the evacuation, including a rather steep ascent of about 300 feet at the end. Walking up that hill would have been unusually difficult.

At about 10:30 AM, while waiting at about 12300 feet for our ride back to Huaraz, my pulse was 100 beats per minute. It rose to 105 when we rode through the pass at 15580 feet at 1 PM that afternoon. An hour later, after descending in the minivan to New Yungay at 8200 feet, my pulse rate was 60 . I had no further symptoms or tachycardia, even after ascending to Huaraz. The next day, in Huaraz, my awakening pulse rate was 56.

At the insistence of the emergency physician, I took $30 \mathrm{mg}$ of nifedipine at about $7 \mathrm{AM}$ and again at about 10:30 AM. The only effects I could detect were nausea that came on after I had descended and persisted until I went to sleep that night, and heartburn that lasted all of the next day in spite of omeprazole.

This experience suggests several aspects of acute altitude illness that could be investigated profitably:

1. I appear to have a unique susceptibility to re-entry altitude illness. I am probably not the only person with that susceptibility. (Two women in our group developed generalized edema after descending to Machu Picchu and returning to Cuzco. Two others noticed aggravation of edema they had already observed at Cuzco.)

2. Hultgren has emphasized the value of tachycardia as a confirmatory feature of HAPE. Perhaps it is an early sign that, along with fatigue, can alert individuals that the disorder may be developing.

3. Monitoring pulse rate may be a reliable method for evaluating the progress of HAPE.

James A. Wilkerson III, MD Merced, CA, USA 